\title{
Effect of a Prior-Authorization Requirement on the Use of Nonsteroidal Antiinflammatory Drugs by Medicaid Patients
}

\author{
Walter E. Smalley, Marie R. Griffin \\ Randy L. Fought, Leo Sullivan \\ Wayne A. Ray
}

BACKGROUND:

Prior authorization-mandatory advance approval for the use of expensive medications-is now the primary method by which Medicaid programs control expenditures for drugs. However, whether this policy reduces expenditures for specific drugs without causing the unwanted substitution of other drugs or medical services has been largely unstudied. We evaluated the effects of a prior-authorization policy involving nongeneric nonsteroidal antiinflammatory drugs (NSAIDs) in the Medicaid program in Tennessee.

\section{METHODS:}

We compared monthly Medicaid expenditures that were potentially affected by the policy change during the year before and the two years after its implementation. We studied prescriptions for NSAIDs, other analgesic or antiinflammatory drugs, and psychotropic drugs, as well as outpatient services and inpatient admissions for the management of pain or inflammation.

\section{RESULTS:}

At the midpoint of the base-line year, 495,821 people were enrolled in Medicaid. During that year, mean annualized Medicaid expenditures for NSAID prescriptions amounted to $\$ 22.41$. Expenditures decreased by $53 \%$ ( $95 \%$ confidence interval, 48 to $57 \%$ ) during the next two years, for an estimated savings of $\$ 12.8$ million. The reduction in expenditures resulted from the increased use of generic NSAIDs, as well

\begin{abstract}
as from a $19 \%$ decrease in overall NSAID use (95\% confidence interval, 13 to $25 \%)$. There was no concomitant increase in Medicaid expenditures for other medical care. Regular users of nongeneric NSAIDs, those most affected by the policy change, had similar reductions in NSAID expenditures and use, with no increase in expenditures for other medical care.
\end{abstract}

\section{CONCLUSION:}

Prior-authorization requirements may be highly cost effective with regard to expenditures for NSAIDs, drugs that have very sim. ilar efficacy and safety but substantial variation in cost.

J Managed Care Pharm 1996:2:158-164.
Controlling expenditures for drugs is an important part of cost containment in the Medicaid program. In the 10 years from 1984 through 1993, these expenditures increased fourfold, from $\$ 1.97$ billion to $\$ 7.97$ billion, ${ }^{1}$ as a result of increases in enrollment, use of medication, and unit costs. ${ }^{2}$ Medicaid programs are therefore taking more aggresive steps to contain drug costs., ${ }^{3,4}$

The Omnibus Budget Reconciliation Act of 1990 established prior authorization as the primary way for Medicaid programs to control drug expenditures. This policy restricts the use of services by requiring pharmacies to obtain advance approval before dispensing certain drugs, usually effective drugs for which there are less costly therapeutic alternatives. The attractiveness of such selective control is that it can decrease costs without denying patients access to needed medications. Other policies designed to control expenditures, such as the shifting of costs to patients or the use of highly restrictive formularies, may disproportionately affect the elderly and the very ill, decrease access to essential medications, lead to undesirable drug substitutions, or increase the use of more expensive medical care. 5-9

The Omnibus Budget Reconciliation Act required states to include nearly all pharmaceuticals under Medicaid coverage, but it permitted prior-authorization programs. According to the act, states had to provide unrestricted coverage that included most new products for at least six months after their approval by the Food and Drug Administration. As of 1992, Medicaid programs in 34 states had implemented

\section{$\Delta \quad$ Authors}

WALTER E. SMALLEY, M.D., is from the Division of Gastroenterology, MARIE R. GRIFFIN, M.D., M.P.H., is from the Division of General Internal Medicine, RANDY L. FOUG.HT, B.S., and WAYNE A. RAY, PH.D., are from the Department of Medicine and Department of Preventive Medicine, Vanderbilt University School of Medicine, Nashville, Tennessee.

LEO SULLIVAN, D.PH., is from the Tennessee State Department of Health, Bureau of TennCare, Nashville, Tennessee.

Reprints: Walter E. Smalley, Department of Preventive Medicine, A-1.124 MCN, Vanderbilt University School of Medicine, Nashville, TN $37232-2637$.

ACKNOWLEDGMENTS: Reprinted by permission of The New England Joumal of Medicine. Volume 332, Number 24, June 15. 1995, pages 1612-1617. This project was supported in part by a grant (HS07768) from the Agency for Health Care Policy Research and by a cooperative agreement (FD-U-0000073) with the Food and Drug Administration. Dr. Smalley was supported in part by a Ciba-Geigy Fellowship in Pharmacoepidemiology.

Copyright $\bigcirc$ 1995, Massachusetts Medical Society. All rights reserved 
Figure 1A. Annualized Rates of Expenditure for NSAIDs among All Enrollees in Tennessee Medicaid for Each Month before and after the Implementation of the Prior-Authorization Policy.

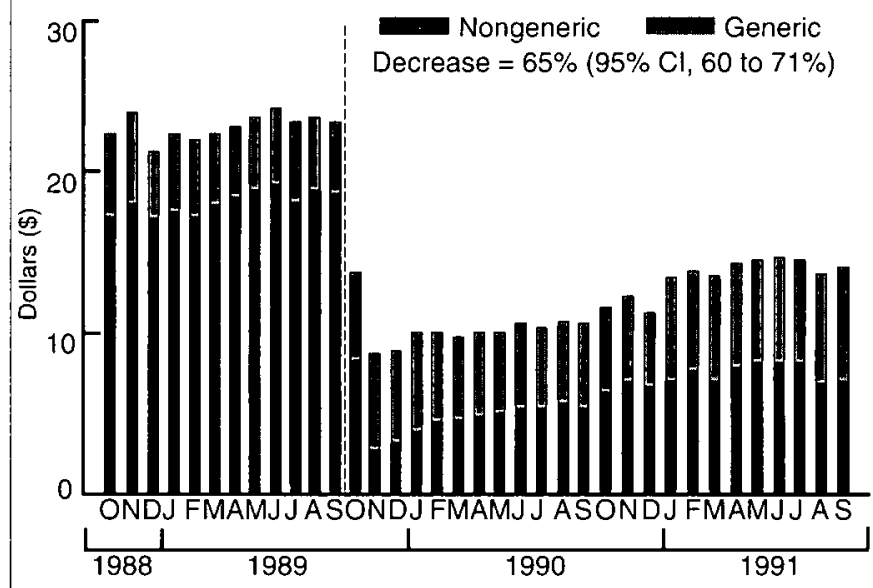

Figure 1B. Number of Days of NSAID Use among All Enrollees in Tennessee Medicaid for Each Month before and after the Implementation of the Prior-Authorization Policy

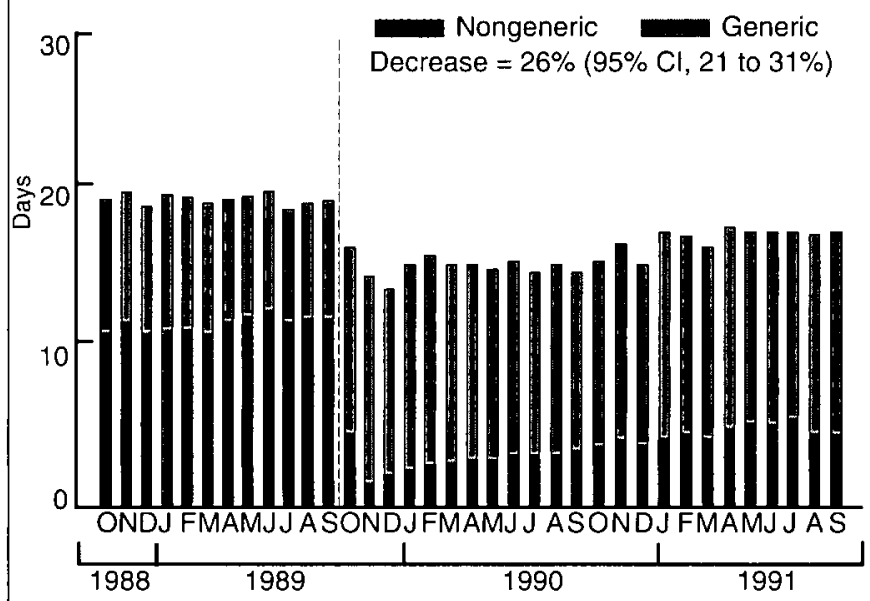

The dashed line indicates the date of implementation. The percent decrease that was estimated in the interrupted time-series analysis to be the immediate effect of the program is shown, followed in parentheses by the $95 \%$ confidence interval $(\mathrm{Cl})$.

prior-authorization programs. ${ }^{4}$ Despite the widespread use of these programs, however, there have been no well-controlled studies of the effectiveness of the policy. 10 Adverse clinical and economic effects are both possible. Limiting access to effective drugs may lead to undesirable drug substitutions (e.g., that of a barbiturate for a benzodiazepine) or to the increased use of medical services (e.g., additional office visits to identify an effective approved drug).

In October 1989, the Medicaid program in Tennessee, Tennessee Medicaid, established a requirement for prior authorization of the prescription of nonsteroidal antiinflammatory drugs (NSAIDs) not available generically. For several reasons, NSAIDs were excellent candidates for this program.
Figure 2A. Annualized Rates of Expenditure for Other Analgesic and Antiinflammatory Drugs among All Enrollees in Tennessee Medicaid for Each Month before and after the Implementation of the Prior-Authorization Policy.

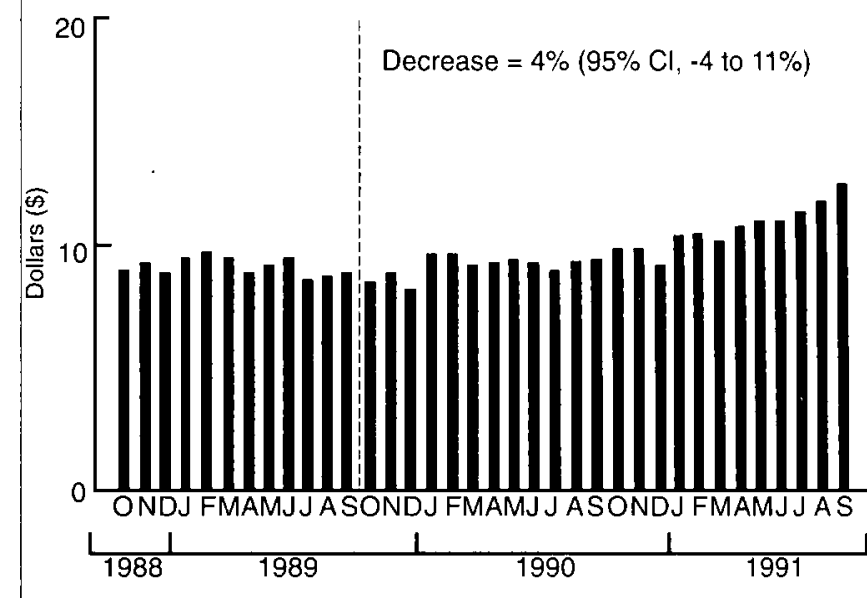

Figure 2B. Annualized Rates of Expenditure for Outpatient Services among All Enrollees in Tennessee Medicaid for Each Month before and after the Implementation of the Prior-Authorization Policy.

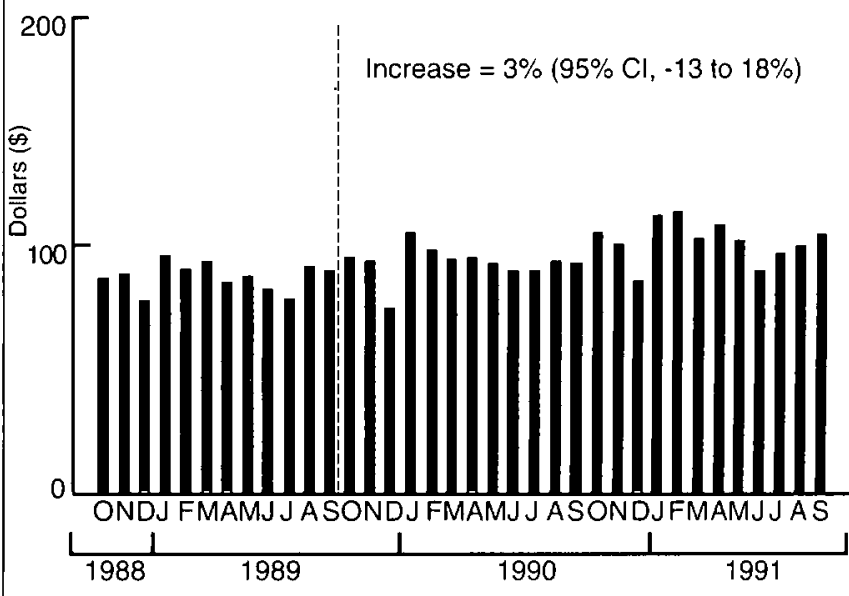

The dashed line indicates the date of implementation. The percentage increase or decrease that was estimated in the interrupted timeseries analysis to be the immediate effect of the program is shown, followed in parenthesses by the $95 \%$ confidence interval $(\mathrm{Cl})$.

They are among the most frequently used medications in the United States, with 70 million prescriptions filled in 1.991 (3.8\% of all prescriptions) at a cost of a about $\$ 2.2$ billion. 11 In Tennessee, during the year before the policy change, NSAIDs made up $11 \%$ of the expenditures of the Medicaid pharmacy program, which totaled $\$ 99$ million. Prices for individual NSAIDs vary substantially; the more expensive agents cost up to 1.2 times as much as generic ibuprofen. 12 Although the majority of NSAIDs prescribed are the more expensive ones, ${ }^{13}$ no specific NSAID has been shown to have superior efficacy or lower overall toxicity than the others. ${ }^{14}$

We used a longitudinal Medicaid data base ${ }^{15}$ to study the 
effects of the Tennessee requirement. We sought to quantify the effects of the pollicy change on the prescription of NSAIDs and to determine whether there were unanticipated increases in the use of other medications or medical services.

\section{METHODS}

\section{The Prior-Authorization Requirement}

Beginning on October 1, 1989, Tennessee Medicaid required that prior authorization be given to reimbursement of all prescription NSAIDs except those available generically at that time (ibuprofen, indomethacin, fenoprofen, meclofenamate, mefenamic acid, phenylbutazone, and aspirin). Obtaining this authorization required that the physician certify that the patient had an arthritic or other connective-tissue disorder and had recently tried using a generic NSAID for at least two months, without success. Physicians submitting prior-authorization requests to Medicaid (by mail, fax, or a toll-free telephone line beginning November 1, 1990), and these were initially reviewed by a nurse. Requests that were not approved at this stage were also reviewed by a doctoral-level pharmacist or a physician. The response was mailed or faxed to the physician within 48 hours of the receipt of a mailed request, and responses to telephoned requests were usually given at the time of the initial contact. Authorizations were initially valid for only 12 months, but those issued after August 1990 were effective indefinitely. Patients who had prescriptions for a nongeneric NSAID in September 1989 automatically had prior authorization granted for one month. The estimated costs of the program were approximately $\$ 75,000$. per year.

\section{Design and Sources of Data}

We compared the Medciaid costs and use of NSAIDs and other health care services potentially affected by the policy change during the base-line year before the implementation of the requirement (October 1, 1988, through September 30, 1989) with those in the two-year period after the change (October 1, 1989, through September 30, 1991). Computerized Medicaid files contained data on enrollment status and reimbursement of claims for medical care for all Medicaid beneficiaries (approximately $12 \%$ of the state population). ${ }^{15}$ The files for each reimbursement included a unique recipient number and the name of the service provider, the date of service, and the Medicaid payments (as well as any applicable Medicare payments). The files used included those for pharmacy services (showing the drug, dosage, and number of days for which medication was supplied for outpatients), outpatient visits (those to physicians, other professionals, and hospital emergency departments), inpatient admissions, and stays in a skilled nursing facility.

\section{Study Groups}

\section{All Medicaid Enrollees}

Because the prior-authorization policy applied to the entire Medicaid program, the first group studied consisted of all persons enrolled in Medicaid at any time during the three-year period. The analysis of this group provided the most comprehensive assessment of the effects of the policy change. However, it had limited sensitivity for adverse effects of the policy, because enrollees who did not use NSAIDs (the majority) were unaffected by the prior-authorization requirement.

\section{Regular NSAID Users}

To provide a more sensitive assessment of the effects of the policy change, we conducted a separate analysis of regular users of NSAIDs. These were defined as all enrollees with uninterrupted enrollment in Medicaid for the entire 36 months of the study, a Medicaid prescription for an NSAID that was dispensed in the month before the implementation of the prior-authorization policy (September 1989), and at least 274 days for which an NSAID was prescribed $(75 \%$ of the baseline year) except for aspirin taken at a dosage of less than 325 $\mathrm{mg}$ per day. This cohort was further restricted to those who had received only nongeneric or only generic NSAIDs, but not both, in the base-line year. The former group provided a sensitive indicator of the effects of the policy change on other medical care, because the physicians involved would need either to obtain prior authorization or to prescribe other medications. The latter group served as controls for the natural history of NSAID use and secular trends in such use.

\section{Study Outcomes}

The study focused on pharmacotherapy, outpatient services, and inpatient admissions for the management of pain or inflammation, the areas most plausibly affected by the regulatory change. The analysis was restricted to services for which Medicaid or Medicare payment was made. Medical care and payments were assigned to the month in which the service began. We also analyzed the use of all other nonstudy care, as an indicator of changes in the Medicaid population or secular trends in the use of medical care.

\section{Pharmacotherapy}

We tabulated Medicaid payments and days of drug use for nongeneric and generic NSAIDs. We also tabulated payments for other analgesic or antiinflammatory drugs (acetaminophen, opioid analgesics, injectable and oral corticosteroids, skeletal-muscle relaxants, methotrexate, gold, penicillamine, azathioprine, and hydroxychloroquine) and psychotropic drugs (antidepressant, hypnotic, and anxiolytic agents).

\section{Outpatient Services}

The ouptatient services included in the study were those provided by physicians, osteopathic physicians, chiropractors, nurse practitioners, and physical or occupational therapists for which there were study procedure codes and that were not provided during an inpatient stay. The study procedure codes (available from the authors on request) were those for routine visits (office, nursing home, or home visits), physical medicine, or radiologic examinations of the hip or knee. This broad 
Table 1. Characteristics of Enrollees in Tennessee Medicaid before and for Two Years after the Implementation of the Prior-Authorization Policy ${ }^{\mathrm{a}}$

\begin{tabular}{|c|c|c|c|}
\hline \multirow[b]{2}{*}{ Variable } & \multicolumn{3}{|c|}{ No. of Enrollees } \\
\hline & Base-line Year & Year 1 & Year 2 \\
\hline \multicolumn{4}{|l|}{ No. of enrollees } \\
\hline at mid-year & 495,821 & 544,140 & 547,403 \\
\hline \multicolumn{4}{|l|}{ Age (yr) } \\
\hline$<18$ & 43.6 & 44.5 & 45.2 \\
\hline $18-44$ & 26.9 & 26.7 & 26.6 \\
\hline $45-64$ & 10.8 & 10.7 & 10.6 \\
\hline$\geq 65$ & 18.8 & 18.1 & 17.7 \\
\hline \multicolumn{4}{|l|}{ Sex } \\
\hline Female & 63.6 & 63.2 & 62.9 \\
\hline Male & 36.4 & 36.8 & 37.1 \\
\hline \multicolumn{4}{|l|}{ Race } \\
\hline Black & 39.3 & 38.0 & 38.4 \\
\hline Other & 60.7 & 62.0 & 61.6 \\
\hline \multicolumn{4}{|l|}{ Place of residence } \\
\hline Community & 95.0 & 95.3 & 95.5 \\
\hline Nursing Home & 5.0 & 4.7 & 4.5 \\
\hline \multicolumn{4}{|l|}{ County of residence } \\
\hline SMSA ${ }^{b}$ & 64.2 & 64.1 & 64.0 \\
\hline Other & 35.8 & 35.9 & 36.0 \\
\hline \multicolumn{4}{|c|}{ Nonstudy medical care ${ }^{\mathrm{C}}$} \\
\hline Prescriptions & 10.7 & 10.5 & 11.3 \\
\hline Outpatient claims & 4.6 & 4.9 & 5.0 \\
\hline Inpatient days & 3.0 & 3.1 & 2.5 \\
\hline
\end{tabular}

definition was chosen because physicians might have treated pain or inflammation during the course of visits for other health problems and because the Medicaid diagnostic data for visits to physicians during the study period were incomplete for persons 65 years of age or older. ${ }^{15}$ We also included visits to the emergency department of a hospital for which the diagnosis indicated a musculoskeletal disorder (codes 710 through 739 of the International Classification of Diseases, 9 th Revision, Clinical Modification ${ }^{16}$ ). Diagnoses made in the emergency department were thought to be more specific than those made during visits to a physician and were available for the entire study population. Study payments for outpatient visits included only payments for study procedures; those for visits to the emrgency department included payments for all outpatient services provided on the day of the visit.

\section{Inpatient Admissions}

Study hospitalizations were those in which the diagnosis listed first was a musculoskeletal disorder or in which there was an associated claim by the physician indicating surgery for total replacement of the knee, hip, or elbow. Inpatient payments also included payments for stays in a skilled nursing facility for up to 30 days after hospitalization.

\section{Statistical Analysis}

Rates were calculated by dividing expenditures or use of services during a period of time by the corresponding number of person-years of enrollment in Medicaid. These annualized rates provided comparability between periods of different lengths.

For the study group comprising all Medicaid enrollees, we conducted two analyses of the effect of the policy change. The first was an interrupted time-series analysis, which provided the best estimate of the immediate effect of prior authorization. The series consisted of the 36 monthly values for the outcomes variables (such as the annualized rate of expenditures for NSAIDs). The segmented regression model was as follows:

$$
\begin{aligned}
& Y=B_{0}+B_{1}(M-1)+B_{2} X_{13}+B_{3} X_{14-25}(M-14)+ \\
& B_{4} X_{26-36}(M-26)+\Delta X_{A F T},
\end{aligned}
$$

where $B_{1}$ represents any secular trend before the policy change (during months $I$ through 12 ), $B_{2}$ the one-time effect of the month of transition (month 13), $B_{3}$ and $B_{4}$ changes in the secular trend in the first year (months 14 through 25) and the second year (months 26 through 36 ) after the change, $\triangle$ the immediate effect of the policy change, $M$ month, and $X$ design varaibles. In the estimation of parameters, a lirst-degree autocorrelation was assumed (SAS Proc Autoreg).

We also performed a more conservative summary analysis that estimated the overall change between the base-line year and the period after the change, excluding month 13; this analysis accounted for rebound effects as providers became more familiar with the policy. We used weighted least squares (SAS Proc Reg), with the demographic stratum as the unit of analysis and the corresponding numbers of person-years of enrollment in Medicaid as the weights.

The study of the effects of the policy change on regular users of NSAIDs used an interrupted time-series analysis with a control analysis. ${ }^{5}$ The series of interest was that of regular users of nongeneric NSAIDs before the policy change; the control series, that of comparable users of generic NSAIDs.

All the analyses used SAS version 6.08 on an Intel 486 computer with Windows 3.11 .

\section{RESULTS}

\section{All Medicaid Enrollees}

Midyear enrollment in Tennessee Medicaid increased from 495,821 in the base-line year to 547,403 two years later (during the second year after the implementation of prior authorization) (Table 1). The characteristics of the population in each study were generally comparable: $44 \%$ of enrollees were under 18 years of age, $63 \%$ were female, $38 \%$ were black, $5 \%$ lived in nursing homes, and 64\% lived in Standard Metropolitan Statistical Areas.

Although the use of nonstudy medical care remained generally similar throughout the study period (Table 1), some minor trends were noted. In the second year after the policy change, Medicaid prescriptions for nonstudy drugs increased by $8 \%$, an increase that corresponded to the implementation of the provisions in the Omnibus Budget Reconciliation Act of 
Table 2. Use of and Expenditures for NSAIDs among All Enrollees in Tennessee Medicaid, before and after the Implementation of the Prior-Authorization Policy

\begin{tabular}{|c|c|c|c|c|}
\hline \multirow[b]{2}{*}{ Type of NSAID } & \multirow[b]{2}{*}{ Base-line Year } & \multicolumn{2}{|c|}{ Rate/person-year $(95 \% \mathrm{Cl})^{\mathrm{C}}$} & \multirow{2}{*}{$\begin{array}{c}\text { Difference in Overall } \\
\text { Expenditures }(\$)^{\mathbf{b}}\end{array}$} \\
\hline & & Next Two Years ${ }^{\mathbf{a}}$ & Difference ${ }^{b}$ & \\
\hline \multicolumn{5}{|l|}{ Nongeneric } \\
\hline Days used & $10.72(10.111011 .33)$ & $3.16(3.01$ to 3.31$)$ & $-7.56(-8.0410-7.07)$ & \multirow{2}{*}{$-14,005,613$} \\
\hline Expenditures(\$) & $18.01(17.001019 .01)$ & $5.15(4.90$ to 5.40$)$ & $-12.86(-13.6510-.12 .06)$ & \\
\hline \multicolumn{5}{|l|}{ Generic } \\
\hline Days used & $8.32(7.88108 .75)$ & $12.20(1.1 .7410 .12 .66)$ & $3.89(3.16104 .62)$ & \multirow{2}{*}{$1,167,805$} \\
\hline Expenditures (\$) & $4.40(4.17104 .63)$ & $5.47(5.28$ to 5.66$)$ & $1.07(0.75$ to 1.39$)$ & \\
\hline \multicolumn{5}{|l|}{ All } \\
\hline Days used & $19.04(18.01$ to 20.07$)$ & $15.37(14.77$.0 15.97) & $-3.67(-4.79$ (0 -2.54$)$ & \multirow{2}{*}{$-12,837,809$} \\
\hline Expenditures $(\$)$ & $22.41(21.19$ to 23.62$)$ & $10.62(10.191011 .05)$ & $-11.78(-12.8410-10.72)$ & \\
\hline
\end{tabular}

1990 that required unrestricted Medicaid coverage of new drugs for six months. By the second year after the change, claims for outpatient services had increased by $9 \%$, and in that year the number of inpatient days decreased by $1.9 \%$.

In the base-line year, Medicaid paid $\$ 22.41$ ( $95 \%$ confidence interval, $\$ 21.19$ to $\$ 23.62$ ) for NSAID prescriptions for each person-year of enrollment. After the implementation of the prior-authorization policy, there was an abrupt drop in expenditure rates (Figure 1A). The interrupted time-series analysis estimated a decrease in expenditures for NSAIDs of $\$ 14.63$ per person-year, or $65 \%$ (95\% confidence interval, 60 to $71 \%$ ), immediately after the policy change. This resulted from both a shift in use from nongeneric to generic NSAIDs (Figure 1) and a $26 \%$ (95\% confidence interval, 21 . to $31 \%$ ) reduction in the overall number of days of NSAID use (Figure 1B).

When the two years after the start of prior authorization were compared with the base-line year, there was a reduction of $\$ 11.78$, or $53 \%$ ( $95 \%$ confidence interval, 48 to $57 \%$ ), in mean annnualized expenditures for NSAIDs (Table 2). This was less than the immediate effect estimated in the interrupted time-series analysis because there was a slight upward trend in expenditures for NSAIDs after the start of the prior-authorization policy, amounting to $\$ 0.17$ per month $(95 \%$ confidence interval, $\$ 0.02$ to $\$ 0.32$ ). Nonetheless, during the two years after prior authorization began, overall expenditures for NSAIDs were $\$ 1.2 .8$ million less than those projected from expenditures in the base-line year (Table 2). During the two years after the change, the number of days of NSAID use decreased by $19 \%$ ( $95 \%$ confidence interval, 13 to $25 \%$ ).

There was no evidence that the use of other services increased after the policy change. Expenditures for other analgesic and antiinflammatory drugs decreased slightly, by $4 \%$ ( $95 \%$ confidence interval, -4 to $11 \%$ ) immediately after the change (Figure 2A). (The upward trend beginning in the second quarter of the second year after the change was consistent with the increase in the use of all nonstudy drugs in that period.) Similarly, there were no significant changes in expenditures for study outpatient services, which increased by $3 \%$ ( $95 \%$ confidence interval, -13 to $18 \%$ ); in expenditures for
Table 3. Changes in Expenditures for NSAIDs among All Enrollees in Tennessee Medicaid after the Implementation of the Prior-Authorization Policy, According to Demographic Subgroup ${ }^{\mathrm{a}}$

\begin{tabular}{|c|c|c|}
\hline Variable & $\begin{array}{c}\text { Expenditures/Person-year in } \\
\text { Base-line Year (\$) }\end{array}$ & $\begin{array}{l}\text { Change in Next } \\
\text { Two Years }^{b}(\%)\end{array}$ \\
\hline \multicolumn{3}{|l|}{ Age } \\
\hline$<18$ & $0.71(0.65100 .77)$ & $-27.2(-36.1(10-18.3)$ \\
\hline $18-44$ & $14.25(13.37$ to 15.12$)$ & $-48.8(-54.2$ to -43.4$)$ \\
\hline $45-64$ & $61.29(59.641062 .94)$ & $-47.7(-50.2$ to -45.1$)$ \\
\hline$\geq 65$ & $62.67(61.561063 .79)$ & $-54.9(-56.6$ to -53.2$)$ \\
\hline \multicolumn{3}{|l|}{$\operatorname{Sex}$} \\
\hline Male & $13.56(12.2910 .14 .82)$ & $-52.8(-60.910-44.8)$ \\
\hline Female & $27.46(25.61$ to 29.32$)$ & $-52.3(-58.210-46.3)$ \\
\hline \multicolumn{3}{|l|}{ Race } \\
\hline Black & $12.49(11.101013 .88)$ & $-52.7(-62.410-43.0)$ \\
\hline Other & $28.28(26.501030 .06)$ & $-47.2(-52.610-41.7)$ \\
\hline \multicolumn{3}{|c|}{ Place of residence } \\
\hline Community & $20.66(19.16$ to 22.17$)$ & $-5.1 .4(-57.8$ to -45.0$)$ \\
\hline Nursing home & $55.41(53.98$ to 56.85) & $-59.0(-61.1 .10-56.8)$ \\
\hline \multicolumn{3}{|c|}{ Counly of residence } \\
\hline$S M S A^{C}$ & $16.47(15.10$ to 17.83$)$ & $-53.0(-60.2$ to -45.8$)$ \\
\hline Other & $33.12(31.04$ to 35.20) & $-52.4(-57.910-47.0)$ \\
\hline \multicolumn{3}{|c|}{$\begin{array}{l}\text { Numbers in parentheses are } 95 \% \text { confidence intervals. } \\
\text { b The calculations for this period do not include the month of program im- } \\
\text { plementation (October 1989). } \\
\text { C Denotes Standard Metropolitan Statistical Area. }\end{array}$} \\
\hline
\end{tabular}

psychotropic drugs, which decreased by $11 \%$ ( $95 \%$ confidence interval, -4 to $26 \%$ ); or in expenditures for study inpatient admissions, which decreased by $1.4 \%$ (95\% confidence interval, -8 to $36 \%$ ).

Expenditures for NSAIDs decreased substantially within each subgroup defined according to demographic characteristics (Table 3). The change was least pronounced among persons under the age of 18 and most pronounced among those over 65 or who lived in nursing homes.

\section{Regular NSAID Users}

In the base-line year, there were 3,174 regular users of exclusively nongeneric NSAIDs and 1,849 regular users of ex- 
clusively generic NSAIDs. The regular users of nongeneric drugs had mean annualized expenditures for NSAIDs of $\$ 554$ in the base-line year, as compared with $\$ 162$ for the generic users. As compared with the control group of users of generic drugs, the regular users of nongeneric drugs had a relative decrease of $64 \%$ ( $95 \%$ confidence interval, 53 to $75 \%$ ) in expenditures for NSAIDs and a relative decrease of $28 \%$ ( $95 \%$ confidence interval, 1.4 to $44 \%$ ) in the number of days of NSAID use immediately after the policy change. However, there were no relative increases in expenditures for other analgesic and antiinflammatory drugs (relative increase, 1\%; $95 \%$ confidence interval, -8 to $1.0 \%$ ), for study outpatient services (relative decrease, $10 \% ; 95 \%$ confidence interval, -4 to $24 \%$ ), or for psychotropic drugs (relative decrease, $1 \% ; 95 \%$ confidence interval, -9 to $11 \%$ ). Regular users of NSAIDs had too few monthly study inpatient admissions to permit a stable statistical analysis.

If regular users of nongeneric NSAIDs who received higher doses had more severe disease, they might have been more susceptible to adverse effects of the policy change. When regular NSAID users were stratified according to the median base-line dose, ${ }^{17}$ the decrease in expenditures for NSAIDs in the period after the change was similar among users below the median (relative decrease, 52\%; 95\% confidence interval, 51 to $68 \%$ ) and among those above the median (relative decrease, $69 \% ; 95 \%$ confidence interval, 55 to $83 \%$ ). The high-dose group had no concomitant increase in expenditures for other analgesic and antiinflammatory drugs (relative change, 0\%; 95 confidence interval, -11 to $12 \%$ ), study outpatient services (relative decrease, $2 \% ; 95 \%$ confidence interval, -15 to $1.9 \%$ ), or psychotropic drugs (relative decrease, $3 \% ; 95 \%$ confidence interval, -11 to $17 \%$ )

\section{DISCUSSION}

In the population enrolled in Tennessee Medicaid, expenditures for NSAIDs per person-year of enrollment decreased by $53 \%$ during the two years after the implementation of the prior-authorization policy, leading to an estimated savings of $\$ 12.8$ million. Given its low administrative costs, the program was highly cost effective in terms of its direct effect on these expenditures. Although we were initially concerned that the program could lead to a corresponding increase in the use of equally expensive but potentially less desirable drugs, such as opioid analgesics or oral corticosteroids, this did not occur. Furthermore, expenditures for outpatient and inpatient services for the management of musculoskeletal disorders did not increase. These findings were both present in the entire Medicaid population and in a cohort of regular users of nongeneric NSAIDs under study - the patients who would be most affected by the policy change. These data indicate that the prior-authorization program achieved its intended effect of materially decreasing Medicaid expenditures for pharmaceuticals without undesirable changes in the use of other types of medical care.
The retrospective design of the present study precluded analysis of outcomes other than the use of medical care. Thus, we could not assess changes in pain control or functional status, either of which might plausibly worsen if patients did not receive the most effective NSAID. However, our data suggest that if any changes in the quality of life occurred, they were not sufficient to increase the use of other types of medication or the number of visits to physicians. Nor could we study changes in patients' use of medications obtained without a prescription (primarily over-the-counter drugs). However, such use would not affect Medicaid expenditures.

Restricting the study to Medicaid patients limits its generalizability. Except in the case of persons less than 18 years old, however, expenditures for NSAIDs decreased by approximately half in all demographic strata, suggesting that savings of similar magnitude could be obtained in other populations.

Other lindings suggest that prior-authorization requirements for NSAID prescriptions should be considered by other Medicaid programs and managed care organizations. Given the estimated annual expenditure of $\$ 2.2$ billion for prescription NSAIDs in the United States, ${ }^{\prime \prime}$ it is possible that preferential use of less expensive agents could result in an annual savings of more than $\$ 1$ billion. Prior authorization might also be considered for use with other frequenily prescribed classes of drugs, such as antidepressants or antihypertensive agents. Like NSAIDs, the drugs in these classes vary considerably in cost; thus, preferential use of the lower-cost agents could generate substantial savings.

The findings of this study of NSAIDs might not be directly applicable to other drug classes, however. Although the responsiveness of patients to individual NSAIDs may vary for reasons that are yet poorly understood, there is limited evidence of systematic differences in the drugs' mechanisms of action, efficacy, or safety. ${ }^{14}$ In contrast, for other therapeutic classes, such as antidepressant or hypertensive agents, the more diverse pharmacologic properties of individual drugs lead to differences in both efficacy and safety. ${ }^{18}$ The therapeutic effect of NSAIDs for musculoskeletal disorders (the most common indication) is limited to the reduction of symptoms and is only moderate. ${ }^{19,20}$ Thus, there is little risk in an empirical trial of a different drug or even of a period away from the drug. Indeed, the limited efficacy of NSAIDs may partly explain the $19 \%$ overall reduction in NSAID use that occurred after the start of prior authorization. However, requirements to change the medications of patients with well-controlled major depression or hypertension might entail substantial hazards because of the lesser efficacy of the alternative medications or the effects of periods away from the drug. Even if such changes could be made without risk to the patient, the additional visits to physicians could cancel out any savings in the cost of the medication. Thus, although our findings indicaie that prior authorization is an effective means of controlling the cost of NSAIDs, further study of its effects on the use of other classes of drugs is needed. 
References

1. Social Security bulletin annual statistical supplement 1994. Baltimore: Health Care Financing Administration, 1994: 325.

2. Pollard MR, Coster JM. Savings for Medicaid drug spending. Health Aff (Millwood) 1991; 1.0 (2):196-206

3. Soumerai SB, Ross-Degnan D. Experience of state drug benefit programs. Health Aff (Millwood) $1990 ; 9$ (3): 36-54

4. Gondek K. Prescription drug payment policy: past, present, anf future. Health Care Financ Rev 1994; 15: 1-7.

5. Soumerai SB, Ross-Degnan D, Avorn J, McLaughlin TJ. Effects of Medicaid drug-payment limits on admission to hospitals and nursing homes. N Engl J Med 1991; 325: 1.072-7. 6 . Soumerai SB, Avorn J, Ross-Degnan D, Gortmaker $S$. Payment restrictions for prescription drugs under Medicaicl: effects on therapy, cost, and equity. N Engl J Med 1987; 317: 550-6. 7. Soumerai SB, McLaughlin. TJ, Ross-Degnan D, Casteris CS, Bollini P. Effects of limiting Medicaid drug-reimbursement benefits on the use of psychotropic agents and acute mental health services by patients with schizophrenia. N Engl J Med 1994; $331: 650-5$
8. Soumerai SB, Ross-Degnan D, Gortmaker S, Avorn J. Withdrawing payment for nonscientific drug therapy: intended and unexpected effects of a large-scale natural experiment. JAMA 1990; 263: 831-9.

9. Weintraub M, Singh S, Byrne L, Maharaj K, Guttmacher L. Consequences of the $1989 \mathrm{New}$ York State triplicate benzodiazepine prescription regulations. JAMA 1991; 266: 2392-7.

10. Soumerai S, Ross-Degnan D, Fortess EE, Abelson J. A critical analysis of studies of state drug reimbursement policies: research in need of discipline. Milbank Q 1993; 71: 217-52.

11. Anti-arthritic medication usage: 1991 . Stat Bull 1992; 73: 25-34.

12. Olin BR, ed. Drug facts and comparisons. St. Louis: Facts and Comparisons, 1992.

13. Tomita DK, Baum C, Kennedy DL, Knapp DE, Perry ZA. Drug utilization in the United States1987: ninth annual review. Rockville, Md.: Food and Drug administration, 1988. (DHHS publication no. PB89-143325.)

14. Brooks PM, Day RO. Nonsteroidal antiinflammatory drugs-differences and similarities, $\mathrm{N}$ Engl J Med 1991; 324: 1716-25.

15. Ray WA, Griffin MR. Use of Medicaid data for pharmacoepidemiology. Am J Epidemiol 1989; 129:837-49.

16. Department of Healih and Human Services. The international classification of diseases, $9 \mathrm{th}$ rev., clinical modification: ICD-9-CM. 2nd ed. Washington, D.C.: Government Printing Office. 1980

17. Smalley WE, Ray WA, Daugherty J, Griffin MR. Nonsteroidal anti-inflammatory drugs and the incidence of hospitalization for pepic ulcer disease in elderly persons. Am J Epidemiol 1995; I4l: $539-45$

18. Division of Drugs and Toxicology. Drug evaluations annual 1993. Chicago: American Medical Association, 1993.

19. Batchlor EE, Paulus HE. Principles of drug therapy. In: Moskowitz RW, Howell DS, Goldberg VM, Mankin HJ, eds. Osteoarthritis, diagnosis and medical/surgical management. 2nd ed. Philadelphia: W.B. Saunders, 1992: 465-92. 20. Bradley JD, Brandt KD, Katz BP, Kalasinski LA, Ryan SI. Comparison of an antiinflammatory dose of ibuprofen, an analgesic dose of ibuprofen, and acetaminophen in the treatment of patients with osteoarthritis of the knee. N Engl J Med 1991; 325: 87-91 